STRUCTURAL

CHEMISTRY

ISSN 2053-2296

Keywords: editorial; polyoxometalates; chemistry; POM; crystal structure.

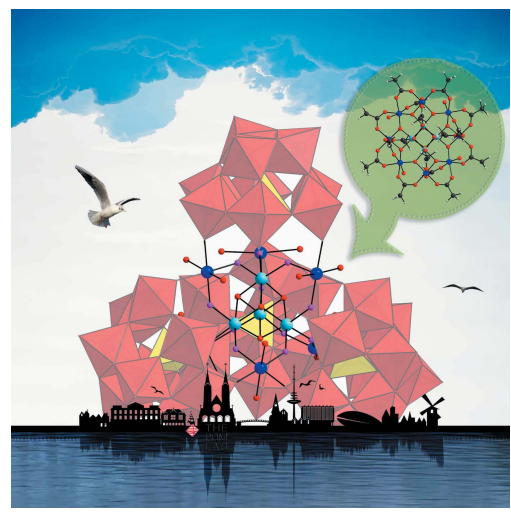

(C) 2018 International Union of Crystallography

\section{Special issue on Polyoxometalates}

\author{
José Ramón Galán-Mascarós ${ }^{\mathrm{a} *}$ and Ulrich Kortz ${ }^{\mathrm{b} *}$
}

${ }^{\mathbf{a}}$ Institute of Chemical Research of Catalonia (ICIQ), Av. Paisos Catalans 16, 43007 Tarragona, Spain, and ${ }^{\mathbf{b}}$ Department of Life Sciences and Chemistry, Jacobs University, Campus Ring 1, 28759 Bremen, Germany. ${ }^{*}$ Correspondence e-mail: jrgalan@iciq.es, u.kortz@jacobs-university.de

We are happy and proud to be guest editors of this special issue on polyoxometalates (POMs), as the year 2018 marks a special anniversary of this exciting class of inorganic compounds for various reasons. The very first POM structure, the so-called Keggin ion $\left(\left[\mathrm{PW}_{12} \mathrm{O}_{40}\right]^{3-}\right.$ ), was structurally characterized by J. F. Keggin in 1933 (so 85 years ago) using powder $\mathrm{X}$-ray diffraction. This was an important breakthrough for POM chemistry, as from then on structural aspects became more relevant and allowed the field to be developed more rationally. Nevertheless, it took several more decades until single-crystal $\mathrm{X}$-ray diffraction became a commonly available analytical technique. The second POM structure, $\left[\mathrm{TeMo}_{6} \mathrm{O}_{24}\right]^{6-}$, was reported by H. T. Evans in 1948 (so 70 years ago). In 1953 (so 65 years ago), the third POM structure, $\left[\mathrm{P}_{2} \mathrm{~W}_{18} \mathrm{O}_{62}\right]^{6-}$, was reported by Dawson. In the same year, Lindqvist reported the structure of $\left[\mathrm{Nb}_{6} \mathrm{O}_{19}\right]^{8-}$. In 1968 (so 50 years ago), Jahr and Fuchs reported on the Lindqvist-type structures $\left[\mathrm{Mo}_{6} \mathrm{O}_{19}\right]^{2-}$ and $\left[\mathrm{W}_{6} \mathrm{O}_{19}\right]^{2-}$. In the same year, the Dexter-Silverton structure, $\left[\mathrm{CeMo}_{12} \mathrm{O}_{42}\right]^{8-}$, was reported. In 1973 (so 45 years ago), the Strandberg-type polyanion structure $\left[\mathrm{P}_{2} \mathrm{Mo}_{5} \mathrm{O}_{23}\right]^{6-}$ was reported. The Müller big-molybdate-ball (Keplerate) $\left[\mathrm{Mo}_{132} \mathrm{O}_{372}\left(\mathrm{CH}_{3} \mathrm{COO}\right)_{30}\left(\mathrm{H}_{2} \mathrm{O}\right)_{72}\right]^{42-}$ was reported in 1998 (so 20 years ago). In 2003 (so 15 years ago), it was demonstrated by Müller and Liu that the Bielefeld big-molybdate wheel $\left\{\mathrm{Mo}_{154}\right\}$ self-assembles in aqueous solution into vesicles. In 2008 (so 10 years ago), Kortz discovered the class of polyoxopalladates and the first member was the $\mathrm{Pd}_{13}$-nanocube $\left[\mathrm{Pd}_{13} \mathrm{As}_{8} \mathrm{O}_{40} \mathrm{H}_{6}\right]^{8-}$. The above represents some common POM structures that have important birthdays in 2018. The actual list of POM structures is of course larger, but most POM structures known to date are based on lacunary (vacant) fragments of the above structures. It should also be noted that Professor M. T. Pope's book entitled 'Heteropoly and Isopoly Oxometalates' was published in 1983, so 35 years ago. Most POM chemists would agree that this is still the best introductory text to the field (>5500 citations). In addition, Professor Pope celebrated his 85 th birthday this year.

Undoubtedly, the development of POM chemistry during the last half-century or so has benefitted tremendously from single-crystal X-ray diffraction. Besides structural aspects, the study of the physicochemical properties of POMs has developed tremendously in recent decades. The multitude of attractive properties includes controllable size, composition, charge density, redox potential, acid strength, high thermal stability in the solid state, solubility in polar/nonpolar solvents and reversible electron/proton storage. Such versatility renders POMs of interest for academic and industrial applications, especially in catalysis. Also other fields such as medicine, magnetism, photochemistry and materials science are being looked at using POMs.

It is also worth mentioning how POM chemistry has contributed to the development of crystallography itself. The presence of POMs (in particular heteropolytungstates) in solution often allows large biomolecules to be crystallized, and facilitates X-ray structure solution and refinement due to their high symmetry, robust molecular structure and heavy-atom content. The history of POMs has progressed from the seminal work of Keggin developing powder X-ray diffraction analysis in the early 20th century, to the role of POMs as cocrystallizing agents for large biologically relevant molecules, such as ribosomes, finally leading to the 2009 Nobel Prize in Chemistry (Yonath, Steitz and Ramakrishnan).

The global POM community is constantly growing and includes researchers from literally all areas of science. In particular, collaborations amongst colleagues from 
different areas of science (experimental or theoretical) seem to drive the field forward. The POM community has held meetings regularly in recent years, e.g. in Bremen (2009), Jerusalem (2010), Honolulu (2010), Lanzarote (2012), Tenerife (2013), Maffliers (2014), Honolulu (2015), Newcastleupon-Tyne (2016), Changchun (2017), Sendai and Tokyo (2018). The next POM meetings are planned for Corvallis,
Oregon (USA) in 2019 and Honolulu, Hawaii (USA) in 2020.

Acta Crystallographica Section $C$ is transforming from a structural (XRD) solid-state journal to a more general journal covering all aspects of structural chemistry and we sincerely hope that this special issue on POMs will assist the journal in achieving its goals. 